\title{
ACUTE BENIGN PERICARDITIS IN INFANCY
}

\author{
BY
}

\author{
W. P. SWEETNAM and C. G. W. SYKES \\ From the Huddersfield and Halifax Hospital Groups
}

(RECEIVED FOR PUBLICATION MAY 23, 1955)

Acute benign pericarditis is becoming more frequently recognized. Carmichael, Sprague, Wyman and Bland (1951) describe a series of 50 cases, and, in a review of the literature, suggest that the syndrome is becoming more common, especially in young adults. Friedman, Ash, Harris and Lee (1952) record the syndrome in infants of 5 months and 3 months of age respectively. A third possible example of the condition is described by Krost (1944), although this infant of 8 months was considered to have rheumatism, a non-specific aetiology seems more probable. Heindl (1948) describes a further case in a 5-month-old infant. The rarity of the syndrome in infancy has prompted us to describe a further case.

\section{Case Report}

A 7-week-old baby girl was admitted to hospital in November, 1954, with dyspnoea and vomiting. The birth weight was $5 \mathrm{lb} .5 \mathrm{oz}$. The child had been well up to eight days previously when she developed a cough and had difficulty in swallowing. Another child in the family had had an upper respiratory infection shortly before.

Physical examination showed a small infant of $8 \mathrm{lb} .9 \mathrm{oz}$. weight with considerable dyspnoea and subcostal recession. Temperature was $99^{\circ} \mathrm{F}$., respirations 100 per minute, pulse 160 per minute. The throat was reddened and oedematous. There appeared to be little chest movement, and practically the whole of the chest was dull to percussion. The heart sounds could be heard but no bruit. A radiograph (Fig. 1) showed an enormously enlarged heart almost filling the whole of the thorax.

In spite of intensive chemotherapy with oxygen, the infant's condition deteriorated. The dyspnoea became more marked and the child became cyanosed. A paracentesis was performed and $25 \mathrm{ml}$. of clear, ambercoloured fluid were removed from the pericardium. The infant's condition improved, the cyanosis and dyspnoea becoming less pronounced. A gradual deterioration took place in the next few days, the cyanosis again becoming marked. A further paracentesis was performed. It was decided to remove as much fluid as possible and $150 \mathrm{ml}$. were aspirated very slowly. A dramatic improvement took place. The cyanosis and dyspnoea disappeared and full feeding was resumed. This procedure was repeated when the clinical condition warranted it. A total of $402 \mathrm{ml}$. of fluid was removed on eight occasions at about seven-day intervals. The last paracentesis was performed three months ago, since when the cardiac outline has remained within normal limits (Fig. 2). The child is now 7 months old, weighs $13 \mathrm{lb} .5 \mathrm{oz}$., and appears a normal thriving infant.

Investigations. A blood count showed a haemoglobin of $14.5 \mathrm{~g}$. per $100 \mathrm{ml}$; red blood cells 4.5 millions per c.mm.; white blood cells 23,000 per c.mm. with a differential count of $64 \%$ polymorphonuclear cells $(1 \%$ eosinophils), $34 \%$ lymphocytes and $2 \%$ myelocytes. The urine was normal. The plasma proteins were $5 \cdot 3 \mathrm{~g}$. per $100 \mathrm{ml}$. with an albumin-globulin ratio of 5.6 to 1. Wassermann and Kahn reactions were negative. The pericardial fluid contained an average of $3 \mathrm{~g}$. of protein per $100 \mathrm{ml}$. with 65 cells per c.mm., $85 \%$ lymphocytes. The pericardial fluid and gastric washings were sterile and the presence of tubercle bacilli could not be demonstrated on culture or on guinea-pig inoculation. The cerebrospinal fluid was normal. Throat swabs failed to grow pathogenic organisms. The only E.C.G. abnormality detected was an elevated RS-T segment. The dye and complement-fixation tests for toxoplasmosis

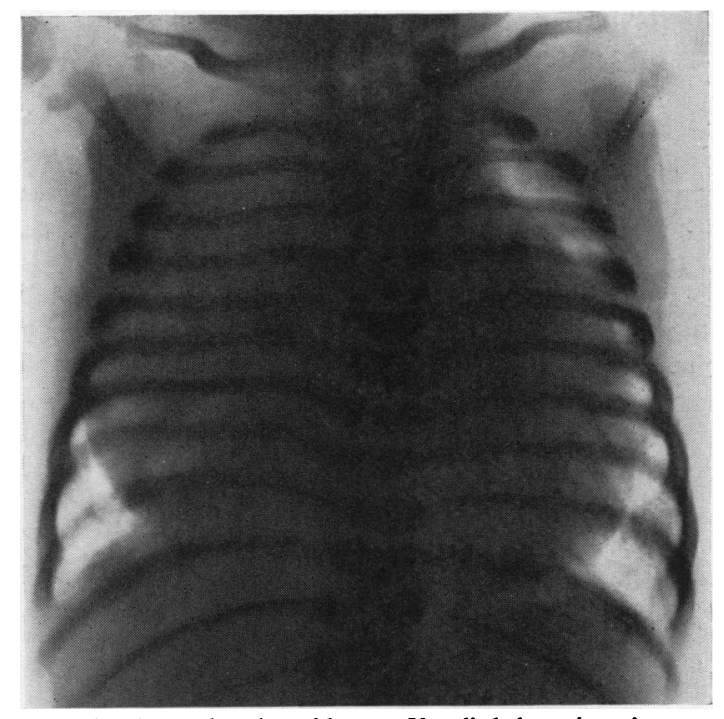

FIG. 1.-A grossly enlarged heart. Very little lung tissue is seen around the central density. 
did not indicate an active infection. The antistreptolysin titre was less than 50 units per $\mathrm{ml}$. Mantoux reactions up to 1 in 100 were persistently negative.

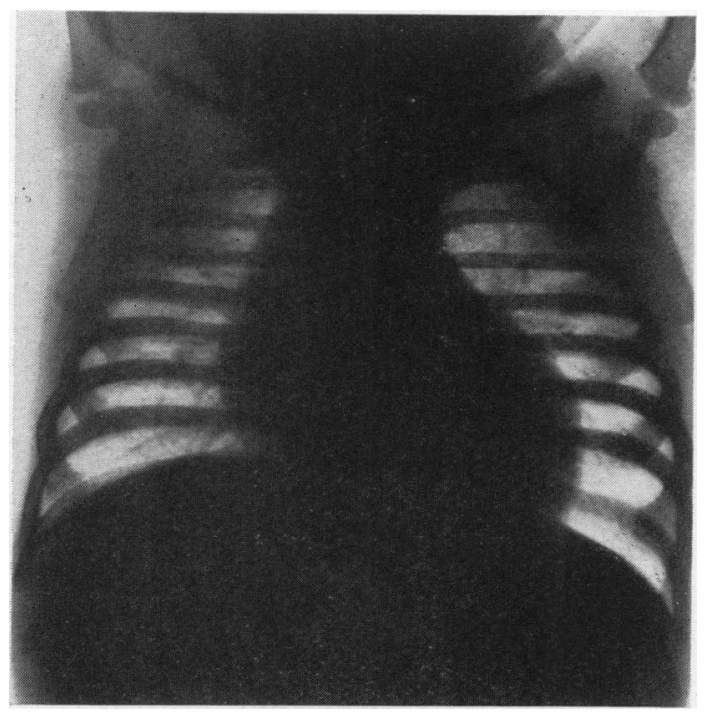

FIg. 2.-The heart shadow within normal limits.

\section{Discussion}

Descriptions of the syndrome all reveal a very similar clinical pattern. An upper respiratory tract infection very commonly preceded the onset of the pericarditis. The immediate prognosis is good, complete recovery taking place. Carmichael et al. (1951) have found a uniformly good prognosis in cases followed up for 15 years and more.

Various antibiotics alone and in combination with cortisone have been used in treatment (Friedman et al., 1952; Martinez and Sariñana, 1950; Taubenhaus and Brams, 1950). It is doubtful, however, whether these drugs have any specific effect on the course of the disease.

The aetiology of the syndrome remains obscure. Among the more likely possibilities are tuberculosis, rheumatism, a hypersensitive response of the pericardium or a virus infection.

No evidence of tuberculosis could be found in this case. A search for a primary focus or contact proved fruitless. The tubercle bacillus could not be demonstrated in stomach washings or pericardial fluid. The Mantoux reactions were persistently negative.

None of the common associated criteria of rheumatism were present. An endocardial bruit was not detected at any stage. The serological evidence failed to substantiate a rheumatic aetiology.

Carmichael et al. (1951) found a large number of cases in their series with a personal or family history of allergy. Pericarditis, clinically indistinguishable from benign non-specific pericarditis, has been reported during serum sickness (McKinlay, 1948). In such cases, eosinophilia has been present; high counts of eosinophils have been demonstrated in the pericardial fluid. These findings were all absent in this case.

The syndrome has been observed in small epidemics in adults. Bing (1933) reported an epidemic of acute benign pericarditis in adults in Copenhagen, six cases being admitted to hospital within a few weeks. The frequent occurrence of an upper respiratory tract infection again suggests an infective origin. The pericardial fluid is invariably sterile. The presence of benign pericarditis in a systemic viral infection has been demonstrated in a case of lymphogranuloma venereum (Sheldon, Wall, Slade and Heyman, 1948). The favourable outcome, apparently uninfluenced by antibiotic therapy, would suggest a viral rather than a bacterial infection.

\section{Summary}

A case of acute benign pericarditis in an infant is described. The aetiology is discussed and the evidence in favour of a virus infection presented.

\section{REFERENCES}

Bing, H. I. (1933). Acta med. scand., 80, 29.

Carmichael, D. B., Sprague, H. B., Wyman, S. M. and Bland, E. F. (1951). Circulation, 3, 321.

Friedman, S., Ash, R., Harris, T. N. and Lee, H. F. (1952). Pediatrics, 9, 551.

Heindl, N. (1948). Öst. Z. Kinderheilk., 1, 315

Krost, G. N. (1944). J. Pediat., 24, 514.

Martinez, P. D. and Sariñana, C. (1950). Bol. méd. Hosp. infant, Méx., 7, 717

McKinlay, C. A. (1948). J. Lancet, 68, 61.

Sheldon, W. H., Wall, M. J., Slade, J. D. and Heyman, A. (1948). Arch. intern. Med., 82, 410.

Taubenhaus, M. and Brams, W. A. (1950). J. Amer. med. Ass., 142, 973. 